\title{
COORDINATION COMPOUNDS OF Cu(II) AND Ni(II) WITH SCHIFF BASES DERIVED FROM FORMYLCARVONE AND o,p-AMINOBENZOIC ACID
}

\author{
Adalgiza Ciobanu", Florica Zalaru*, D. Albinescu* and Christina Zalaru* \\ * Faculty of Chemistry, Organic Chemistry Dept., University of Bucharest, 90-92 \\ Panduri Road, Romania. \\ ** Faculty of Chemistry, Inorganic Chemistry Dept., University of Bucharest, 23 \\ Dumbrava Rosie, Romania.
}

\begin{abstract}
Copper(II) and nickel(II) complexes employing the Schiff bases derived from formylcarvone and ortho and para aminobenzoic acid $(L)$ have been prepared. The complexes of general formula $\mathrm{CuL}_{2} \cdot 2 \mathrm{H}_{2} \mathrm{O}$ and $\mathrm{NiL}_{2} .2 \mathrm{~L}$ have been characterized by elemental analysis, infrared, visible and EPR spectra and thermodifferential analysis. The metallic ion has determined the type of the complex.
\end{abstract}

Keywords: Coordination compounds of $\mathrm{Cu}(\mathrm{II})$ and $\mathrm{Ni}(\mathrm{II})$, Schiff bases derived from formylcarvone.

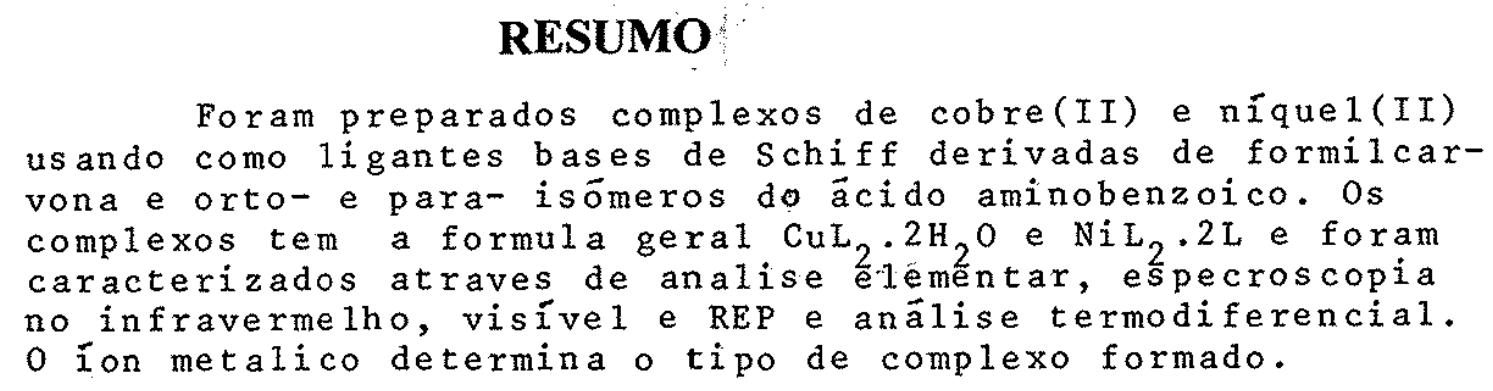




\section{INTRODUCTION}

Schiff bases represent a versatile series of ligands, the metal complexes of which have been widley studied ${ }^{/ 1-5 /}$. Coordination compounds prepared by the reaction of some Schiff bases derived from formylcarvone and o,m,p-toluidine with $\mathrm{Cu}$ (II) and $\mathrm{Ni}(\mathrm{II})$ acetates have been previously described ${ }^{16 /}$.

This paper describs analogous compounds prepared by reaction of some Schiff bases derived from fromylcarvone and ortho and para benzoic amino acid by the type:

where $\mathrm{R}=-\mathrm{COOH}$, ortho and para<smiles>[R]c1cccc(/N=C/C2C(=O)C(C)=CCC2C(=C)C)c1</smiles>

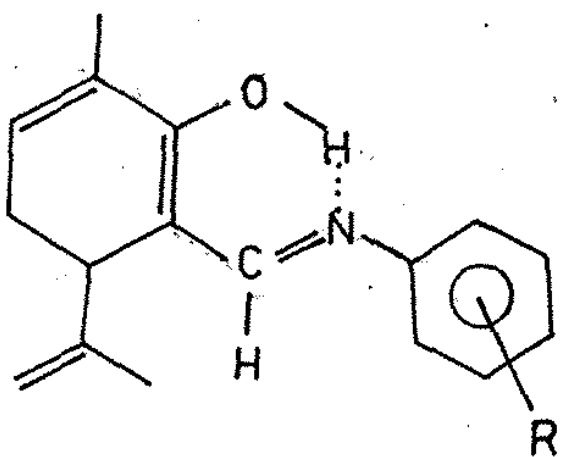

The presence of a $>\mathrm{C}=\mathrm{O}$ group at the 2-position of the carvone ring of the ligand favours a keto-enolic tautomerism (scheme 1). NMR studies have shown that these Schiff bases exist in solution as the enolic tautomer, and that the tautomer distribution was very strongly solvent dependent ${ }^{17,81}$. Such tautomerism has been atributed to intramolecular hydrogen bond formation. Since the oxygen is present as an $\mathrm{OH}$ group, these Schiff bases can act as chelating monoanion. The position of the $\mathrm{COOH}$ substituent of the benzen ring and metallic ion might determine the type of the complex.

\section{EXPERIMENTAL}

The ligands were prepared according to the literature and $\mathrm{Cu}\left(\mathrm{CH}_{3} \mathrm{COO}\right)_{2} \cdot \mathrm{H}_{2} \mathrm{O}$ and $\mathrm{Ni}\left(\mathrm{CH}_{3} \mathrm{COO}\right)_{2} \cdot 4 \mathrm{H}_{2} \mathrm{O}$ p.a. were used. The complex compounds were prepared by mixing warm methanolic solutions $50 \%$ of metal acetate (1 mmole) and ligands (2 mmols and $4 \mathrm{mmols}$ ). The resulting precipitates were filtred and washed with aqueous methanol solution $50 \%$ and dried at room temperature.

The nickel and copper contents were determined gravimetrically analyses. The water content was calculated from the TG curve.

Diffuse reflectance spectra were obtained on VSU 2-P Zeiss Jena spectrophotometer using $\mathrm{MgO}$ as standard.

EPR spectra were recorded at room temperature on polycrystalline powders with an ART 5-IFA Spectrograph. The klystron frequency was $9060 \mathrm{MHz}$ and the modulation of the magnetic field was $100 \mathrm{KHz}$. The EPR spectral parameters were calculated versus a $\mathrm{Mn}$ (II) standard. 
SOUTH. BRAZ. J. CHEM., Vol. 5, $\mathrm{N}^{\circ}$ 5, 1997

Thermodifferential analyses were carried out with a Paulik-Paulik-Erdey derivatograph Q $1500 \mathrm{D}$ MOM. Conditions of measurements: temperature range up to $1000^{\circ} \mathrm{C}$, heating program $10 \mathrm{deg} / \mathrm{min}$, sensivity DTA $=1 / 10, \mathrm{~s}=50, \mathrm{~m}=0.0180 \mathrm{~g} ; 0.0164$ $\mathrm{g} ; 0.024 \mathrm{~g} ; 0.0190 \mathrm{~g}$; atmosphere over sample-air.

IR spectra were recorded within $700-4000 \mathrm{~cm}^{-1}$ range on a Specord 75 Spectrophotometer in $\mathrm{KBr}$ pellet.

\section{RESULTS AND DISCUSSION}

The reaction of metallic acetates with the ligands in water-methanol mixture $=1: 1$ and various $\mathrm{M}: \mathrm{L}$ molar ratios $(1: 1 ; 1: 2 ;$ and1:4) produces the complex compounds of formulas $\mathrm{CuL}_{2} \cdot 2 \mathrm{H}_{2} \mathrm{O}$ and $\mathrm{NiL}_{2} .2 \mathrm{~L}$ (table 1). The isolated compounds contain also molecules of water or ligand either as coordinated and/or as crystalline water.

Table 1: Results of the elemental and thermodifferential analyses.

\begin{tabular}{|c|c|c|c|c|c|c|c|}
\hline No. & Ligand & $\begin{array}{l}\text { Molar } \\
\text { ratio } \\
\mathrm{M}: \mathrm{L}\end{array}$ & Complex & $\begin{array}{l}\mathrm{M} \% \\
\text { found/ } \\
\text { calcd. }\end{array}$ & $\begin{array}{l}\mathrm{H}_{2} \mathrm{O} \% \\
\text { found/ } \\
\text { calcd. }\end{array}$ & $\begin{array}{l}\mathrm{L} \% \\
\text { found/ } \\
\text { calcd. }\end{array}$ & Colour \\
\hline 1. & $R=$ ortho & $1: 2$ & $\mathrm{Cu}(\mathrm{o}-\mathrm{L})_{2} .2 \mathrm{H}_{2} \mathrm{O}$ & $\begin{array}{l}8.08 / \\
9.11\end{array}$ & $\begin{array}{l}4.94 / \\
5.46\end{array}$ & $\begin{array}{l}86.80 / \\
85.52\end{array}$ & $\begin{array}{l}\text { light- } \\
\text { brown }\end{array}$ \\
\hline 2. & $R=$ ortho & $\begin{array}{l}1: 2 \\
\text { and } \\
1: 4\end{array}$ & $\mathrm{Ni}(\mathrm{o}-\mathrm{L})_{2} \cdot 2(\mathrm{o}-\mathrm{L})$ & $\begin{array}{l}4.91 / \\
4.76\end{array}$ & - & $\begin{array}{l}94.85 / \\
95.25\end{array}$ & ochre \\
\hline 3. & $\mathrm{R}=$ para & $1: 2$ & $\mathrm{Cu}(\mathrm{p}-\mathrm{L})_{2} \cdot 2 \mathrm{H}_{2} \mathrm{O}$ & $\begin{array}{l}8.55 / \\
9.11\end{array}$ & $\begin{array}{l}4.44 / \\
5.46\end{array}$ & $\begin{array}{l}86.80 / \\
85.52\end{array}$ & $\begin{array}{l}\text { light } \\
\text { brown }\end{array}$ \\
\hline 4. & $\mathrm{R}=$ para & $\begin{array}{l}1: 2 \\
\text { and } \\
1: 4\end{array}$ & $\mathrm{Ni}(\mathrm{p}-\mathrm{L})_{2} .2(\mathrm{p}-\mathrm{L})$ & $\begin{array}{l}4.66 / \\
4.76 \\
\end{array}$ & - & $\begin{array}{l}94.39 / \\
95.25\end{array}$ & ochre \\
\hline
\end{tabular}

It is noticed that, for nickel(II) ion is obtained the same compound for both Ni:L molar ratio $(1: 2$ or $1: 4)$.

The complex compounds are sparingle soluble in water and soluble in organic solvents (methanol, ethanol, chloroform).

The termodifferential analyses have been confirmed the formulas. Fig. 1 and fig. 2 show the decomposition of the compounds 1 and 2 in detail.

It is clear from the thermogravimetric data that, copper compounds contain water, while nickel compounds do not. The mass loss observed within $120-190^{\circ} \mathrm{C}$ range on TG curve corresponds to the loss of two water molecules per molecule of each of the copper compounds. The thermogravimetric (TG) curve for $\mathrm{Ni}(\mathrm{O}-\mathrm{L})_{2} \cdot 2(\mathrm{O}-\mathrm{L})$ does not 
SOUTH. BRAZ. J. CHEM., Vol. 5, N 5, 1997

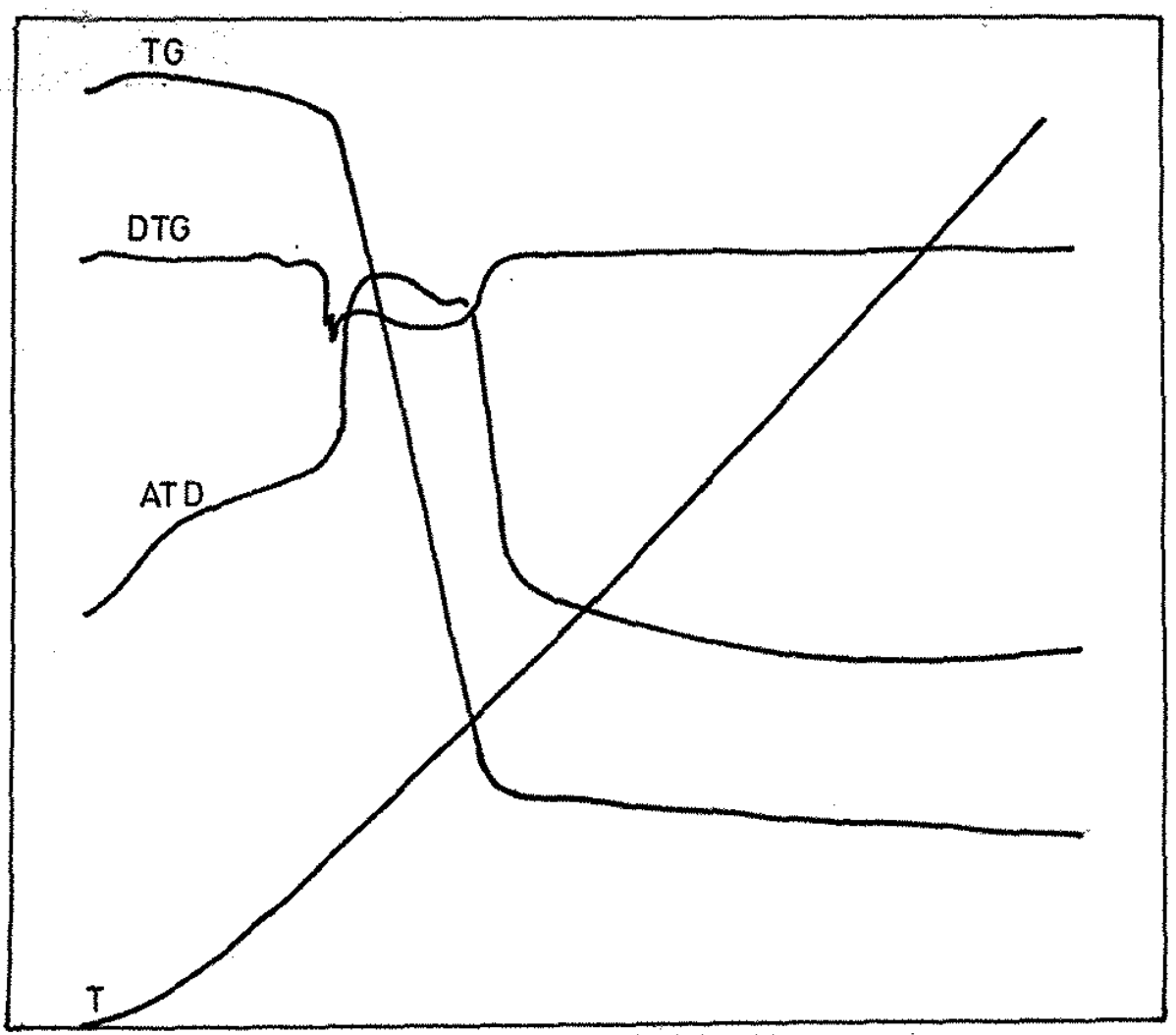

Fig. 1 Thermodifferential curve of $\mathrm{Cu}(\mathrm{O}-\mathrm{L})_{2} \cdot 2 \mathrm{H}_{2} \mathrm{O}$.

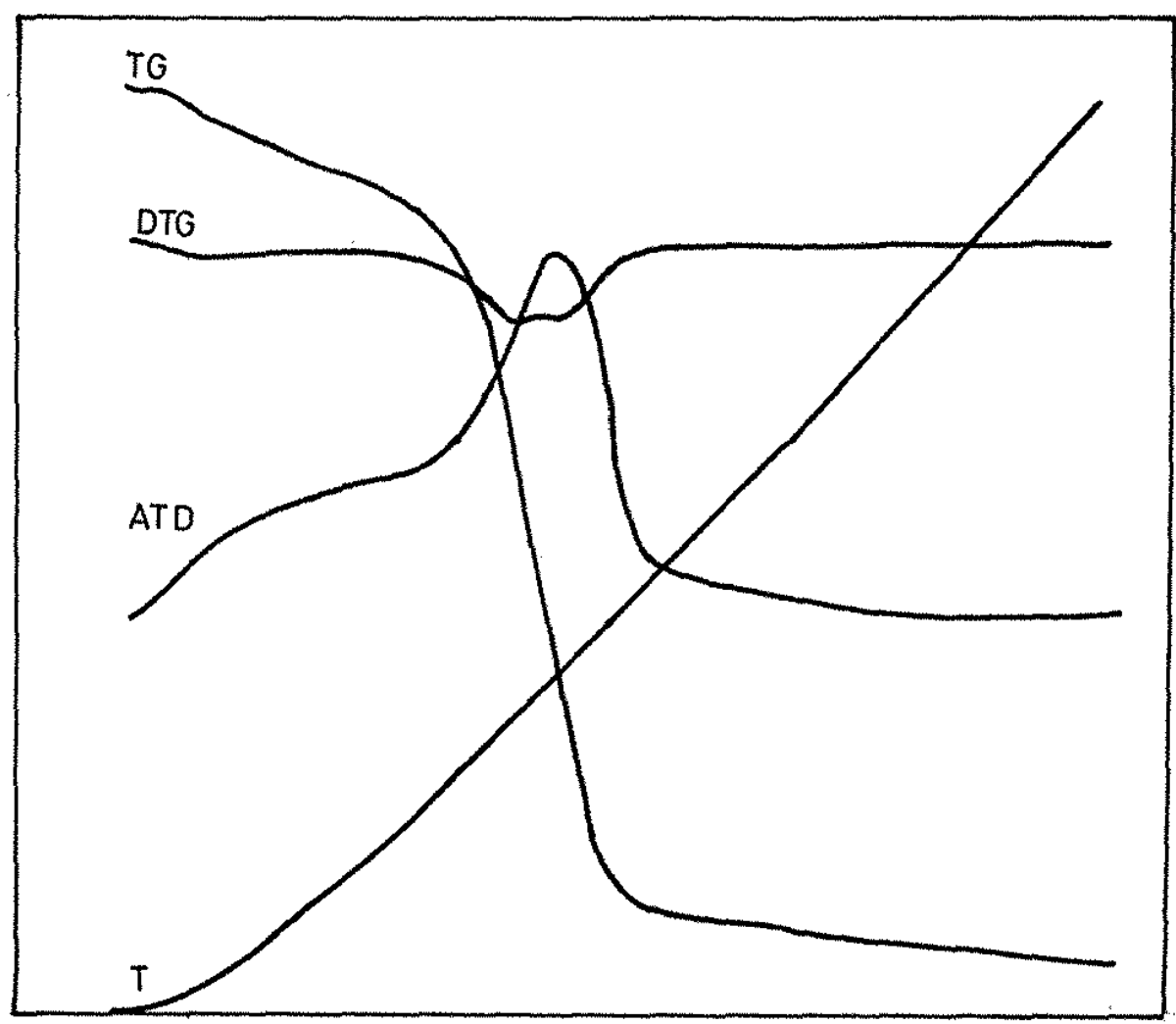

Fig. 2 Thermodifferential curve of $\mathrm{Ni}(\mathrm{O}-\mathrm{L})_{2}, 2(\mathrm{O}-\mathrm{L})$. 
show whether or not the ligand molecules are liberated in steps (weight loss at $190^{\circ} \mathrm{C}$, found: $10.98 \%$ calcd., for $2(0-L): 47.62 \%$.

Diffuse reflectance electronic spectra of $\mathrm{Cu}$ (II) complex compounds are similar; the broad band with a maximum at $700 \mathrm{~nm}$ can be assigned to a d-d transition (fig. 3).

This band can be associated with a distorted octahedron axially ${ }^{j, 10 /}$. The strong broad absorption which occurs at $\sim 400 \mathrm{~nm}$ is assigned to the ligand. Its "tails off" strongly into the visible range.

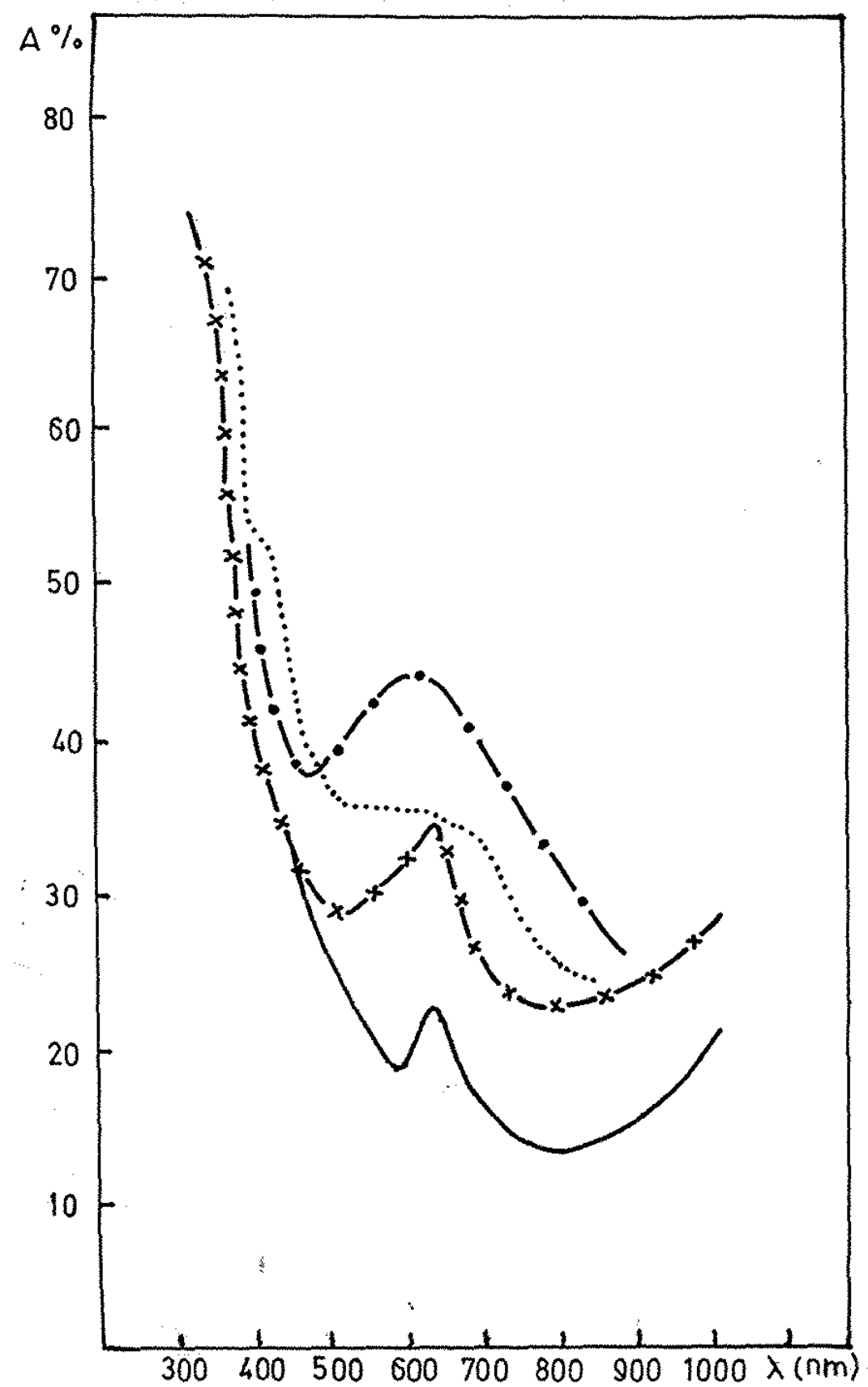

Fig. 3 Electronic reflectance spectra of the compounds:

. . . - Cu(p-L), $2 \mathrm{H}_{2} \mathrm{O} ; \ldots . \mathrm{Cu}(\mathrm{o}-\mathrm{L})_{2}, 2 \mathrm{H}_{2} \mathrm{O}$;

$-x-x-N i(p-L)_{2} \cdot 2(p-L)$

$\mathrm{Ni}(\mathrm{O}-\mathrm{L})_{2} \cdot 2(\mathrm{o}-\mathrm{L})$. 
SOUTH. BRAZ. J. CHEM., Vol. 5, No 5, 1997

Complexes of $\mathrm{Cu}$ and $\mathrm{Ni}$ with Formy leamone

The EPR spectra of both $\mathrm{Cu}(\mathrm{II})$ complex compounds present a similar EPR signal with two $\mathrm{g}$ factors characteristic for the elongated tetragonal octahedral stereochemistry supporting the electronic spectra (fig. 4). The numerical $g$ factors: $\mathrm{g}_{/ /}>>\mathrm{g}_{\perp}>2.0$ suggests a bigger distorsion for $\mathrm{Cu}(\mathrm{p}-\mathrm{L})_{2} \cdot 2 \mathrm{H}_{2} \mathrm{O}$ compound.

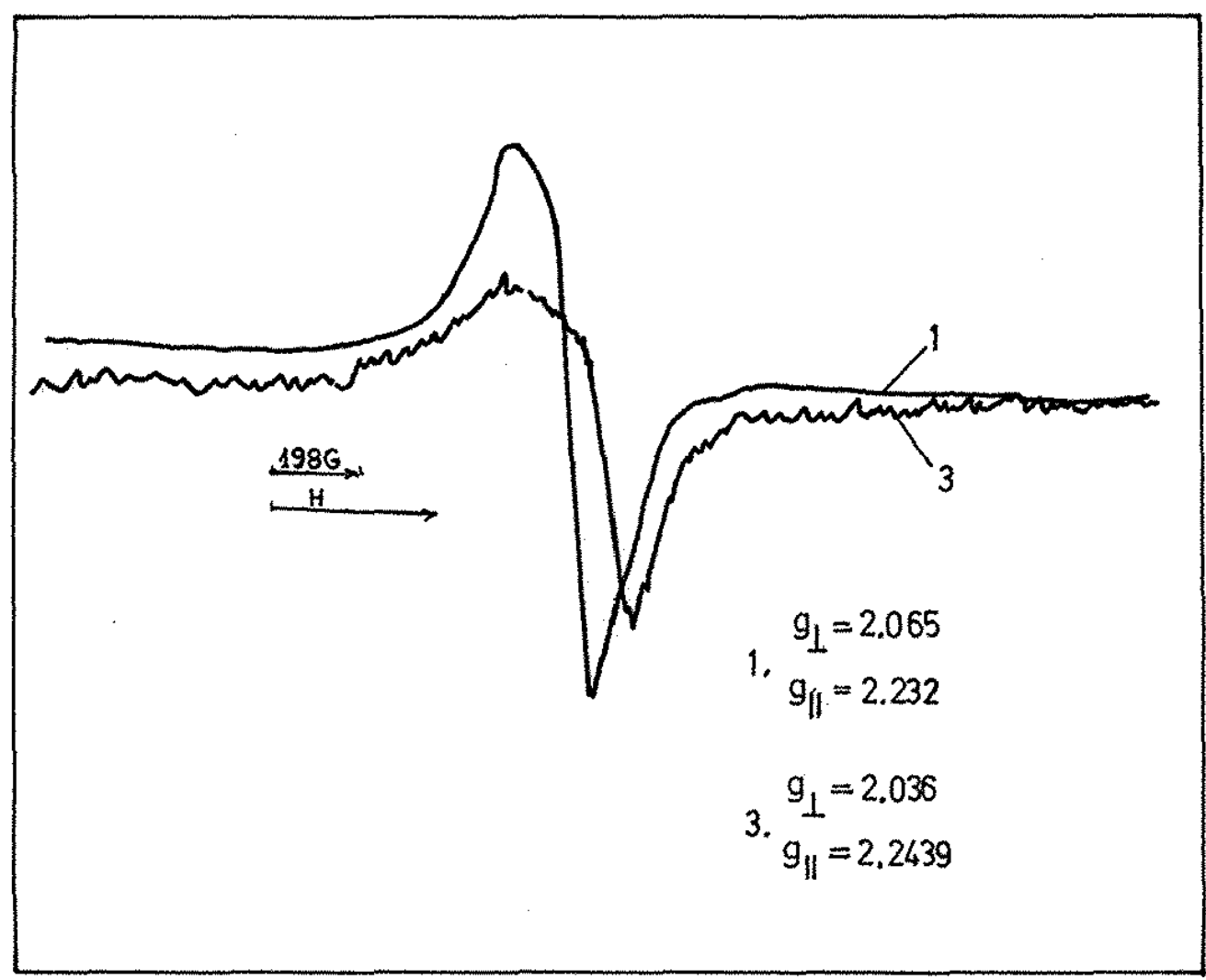

Fig. 4 EPR spectra of the compounds and EPR spectral parameters?

1. $\mathrm{Cu}(\mathrm{o}-\mathrm{L})_{2} \cdot 2 \mathrm{H}_{2} \mathrm{O} ; \quad$ 3. $\mathrm{Cu}(\mathrm{p}-\mathrm{L})_{2} \cdot 2 \mathrm{H}_{2} \mathrm{O}$;

The electronic spectra of the Ni(II) complex compounds are similar and are consistent with the postulation that $\mathrm{Ni}(\mathrm{II})$ ion is essentially hexacoordinate ${ }^{11 /}$. The spectra present a band $\left(\lambda \max =730 \mathrm{~nm}, 740\right.$ respectively), $v_{2}$, that could be assigned to ${ }^{3} \mathrm{~A}_{2 \mathrm{~g}} \rightarrow{ }^{3} \mathrm{~T}_{1 \mathrm{~g}}$ (F) transition. The band $v_{3}(\lambda \max \sim 400 \mathrm{~nm})$ assigned to ${ }^{3} \mathrm{~A}_{2 \mathrm{~g}} \rightarrow{ }^{3} \mathrm{~T}_{1 \mathrm{~g}}(\mathrm{P})$ transition could be covered by the very strong ligand band.

Infrared spectra. The most relevant absorption bands in the IR spectra of the free ligands and their complex compounds are shown in table 2.

The keto-enolic tautomerism is suported by presence of the bands due to $v_{\mathrm{OH}}$ and $v_{C}=0$. The spectra of the free ligands are different within $1700-1000 \mathrm{~cm}^{-1}$ range. Thus, the stretching frequencies $v_{\mathrm{C}=0}\left(1700 \mathrm{~cm}^{-1}\right)$ and $v_{\mathrm{C}=\mathrm{N}}\left(1610 \mathrm{~cm}^{-1}\right)$ appear as a strong and broad band with two unresolved peaks $\left(1665\right.$ and $\left.1610 \mathrm{~cm}^{-1}\right)$ for the ortho substituted ligand, but as a very strong band $\left(1610 \mathrm{~cm}^{-1}\right)$ structured in some peaks ( $1680,1650,1550 \mathrm{~cm}^{-1}$ ) for the para substituted ligand. 
The bands due to $v_{\mathrm{OH}}$ and $v_{\mathrm{C}-\mathrm{OH}}$ from the carvone ring and - $\mathrm{COOH}$ group (3400 and $1200 \mathrm{~cm}^{-1}$ respectively) are different, too. These bands are broad for ortho substituted ligand. The electronic and steric effects of the $-\mathrm{COOH}$ substituent may be transmitted to affect the strength of the hydrogen bond $\mathrm{O}-\mathrm{H}$. . . N modifying the capacity of the nitrogen atom for participating in hydrogen bonding ${ }^{18 /}$. The changes noticed in the infrared spectra of the complex compounds $\mathrm{Cu}(\mathrm{O}-\mathrm{L})_{2} \cdot 2 \mathrm{H}_{2} \mathrm{O}$ and $\mathrm{Ni}(\mathrm{O}-\mathrm{L})_{2} .2(\mathrm{O}-\mathrm{L})$ are similar and involve the $v_{\mathrm{OH}}$ and $v_{\mathrm{C}=\mathrm{N}}$ stretching frequencies. The broad band with two peaks $\left(1665\right.$ and $\left.1610 \mathrm{~cm}^{-1}\right)$ is shifted to lower values $\left(1600 \mathrm{~cm}^{-1}\right)$.

Table 2: The main bands in IR( $\left.\mathrm{cm}^{-1}\right)$ and their assignements

\begin{tabular}{|c|c|c|c|c|}
\hline $\begin{array}{l}\text { Ligand } \\
\text { Complex } \\
\text { compound }\end{array}$ & $v_{\mathrm{OH}}$ & $v_{C=0}$ & $v_{\mathrm{C}-\mathrm{N}}$ & $v_{\mathrm{C}-\mathrm{OH}}$ \\
\hline$R=$ ortho & $3000-3400 \mathrm{br}$ & - & $\left.\begin{array}{l}1610 \mathrm{~s} \\
1665\end{array}\right\}$ & $1200 \mathrm{~m}, \mathrm{br}$ \\
\hline $\mathrm{Cu}(\mathrm{O}-\mathrm{L})_{2} \cdot 2 \mathrm{H}_{2} \mathrm{O}$ & $3410 \mathrm{~s}$ & - & $1600 \mathrm{br}$ & $1200 \mathrm{vw}$ \\
\hline $\mathrm{Ni}(\mathrm{O}-\mathrm{L})_{2} \cdot 2(\mathrm{O}-\mathrm{L})$ & $3350-3405 s$ & - & $1600 \mathrm{br}$ & $1200 w$ \\
\hline $\mathrm{R}=$ para & $3405 \mathrm{~m}$ & $1700 \mathrm{vw}$ & $\begin{array}{l}1550 \\
1610 \mathrm{vs} \\
1650 \\
1680\end{array}$ & $\begin{array}{l}1160 \mathrm{~m} \\
1230 \mathrm{vw} \\
1260 \mathrm{~s}\end{array}$ \\
\hline $\mathrm{Cu}(\mathrm{p}-\mathrm{L})_{2} \cdot 2 \mathrm{H}_{2} \mathrm{O}$ & $3410 \mathrm{~s}$ & $1700 \mathrm{vw}$ & $\begin{array}{c}1560 \mathrm{sh} \\
1600 \mathrm{~s} \\
1650 \mathrm{sh}\end{array}$ & $\begin{array}{l}1160 \mathrm{w} \\
1230 \mathrm{vw} \\
1260 \mathrm{~s}\end{array}$ \\
\hline $\mathrm{Ni}(\mathrm{p}-\mathrm{L})_{2} \cdot 2(\mathrm{p}-\mathrm{L})$ & $3410 \mathrm{~s}$ & $1700 \mathrm{vw}$ & $\begin{array}{l}1580 \mathrm{sh} \\
1600 \mathrm{~s} \\
1650 \mathrm{sh}\end{array}$ & $\begin{array}{l}1160 \mathrm{~m} \\
1230 \mathrm{sh} \\
1270 \mathrm{~s}\end{array}$ \\
\hline
\end{tabular}

$\mathrm{vs}=$ very strong; $\mathrm{s}=$ strong; $\mathrm{m}=$ medium; $w=$ weak; $\mathrm{vw}=$ very weak; $\mathrm{br}=$ broad;

$\mathrm{sh}=$ shoulder.

\}$^{*}=$ multiplet structure of the band. 
It is due to $\mathrm{M}<-\mathrm{N}$ bond formation. The band $v_{\mathrm{OH}}\left(3400-3000 \mathrm{~cm}^{-1}\right)$ lost its broad character and is shifted to higher values suggesting that upon coordination intramolecular hydrogen bond $\mathrm{O}-\mathrm{H}$. . .N from the ligand (scheme 1) is destroyed and $\mathrm{O}-\mathrm{M} \leftarrow--\mathrm{N}$ bond is formed in the metal chelates.

The IR spectrum of both compounds: $\mathrm{Cu}(\mathrm{p}-\mathrm{L})_{2} \cdot 2 \mathrm{H}_{2} \mathrm{O}$ and $\mathrm{Ni}(\mathrm{p}-\mathrm{L})_{2} \cdot 2(\mathrm{p}-\mathrm{L})$ presents the changes that involve the $v_{\mathrm{OH}}$ and $v_{\mathrm{C}=\mathrm{N}}$ stretching frequencies suggesting the same donor atoms. Very strong band $\left(1610 \mathrm{~cm}^{-1}\right)$ appears as a strong band $\left(1600 \mathrm{~cm}^{-1}\right)$ with two shoulders (1650 and $1560 \mathrm{~cm}^{-1}$ ).

These Schiff bases containing an $\mathrm{N}, \mathrm{O}$ donor atoms set, upon coordination to metal ion through both $\mathrm{O}$ and $\mathrm{N}$, a decrease of the $v_{\mathrm{C}=\mathrm{N}}$ frequency and a increase of the $v_{\mathrm{OH}}$ frequency are generally noticed $\mathrm{d}^{18 /}$.

These changes correlated with analytical data, electronic and EPR spectra could suggest that ligands are acted bidentately through both $\mathrm{O}$ and $\mathrm{N}$ donor atoms by the deprotonation of the $\mathrm{OH}$ group making evident participation of the ligands in the enolic tautomeric form. $\mathrm{Cu}$ (II) coordinates with four strong bond $\mathrm{N}$ and $\mathrm{O}$ donor atoms in a plane and with weaker bond to axial two molecules of water (Fig. 5).

Octahedral environment of the $\mathrm{Ni}(\mathrm{II})$ ion suggested by electronic spectrum could be achieved by the participation of para-substituted ligand to coordination both bidentately in a plane (through both $\mathrm{O}$ and $\mathrm{N}$ donor atoms) and monodentately axial (through $\mathrm{O}$ atom of the $-\mathrm{COOH}$ group).

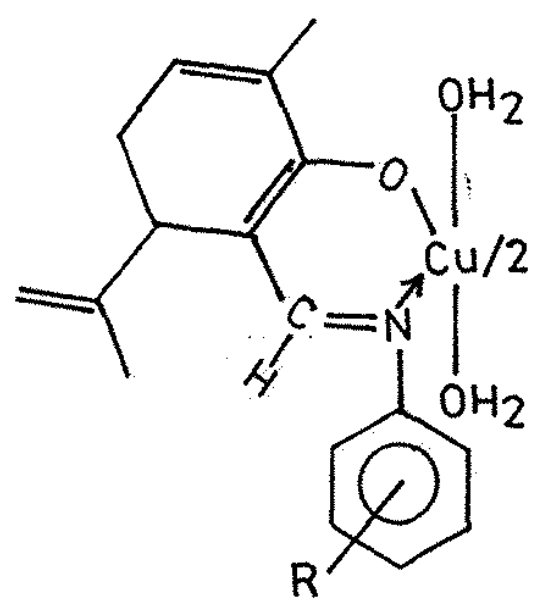

Fig. 5 Structural formula proposed for $\mathrm{Cu}(\mathrm{O}-\mathrm{L})_{2} \cdot 2 \mathrm{H}_{2} \mathrm{O}$

\section{CONCLUSION}

Metallic ion determines the type of the compounds and different coordination behaviours of the ligands. 
SOUTH. BRAZ. J. CHEM., Vol. 5, No 5, 1997

A. Ciobonü, F. Zatgm, D. A̧thinescu \& C. Rolam

\section{REFERENCES}

1. P.C. Chieh and G.J. Palenik, Inorg.Chem., 11, 816 (1972)

2. J. Drummond and J.S. Wood, J.Chem.Soc.Dalton Trans., 365 (1972)

3. M.Di Vaira, P.L. Orioli and L.Sacconi, Inorg Chem., 10, 553 (1971)

4. B. Chiari, O. Piovesana, T. Tarantelli and P.F. Zanazzi, Inorg.Chem., 23, 2542, 3398 (1984)

5. C.T. Spencer and L.T. Taylor, Inorg.Chem., 10, 2407 (1971)

6. P. Grandclaudon, F. Zalaru, D. Albinescu, A. Ciobanu and A. Meghea, Anal.Univ.Buc.Chimie, III, (1996) in press

7. G.O. Dudek and G.P. Volpp, J.Am.Chem.Soc., 85, 2697 (1964)

8. G.C. Percy, J.Inorg.Nucl.Chem., 34, 3357 (1972)

9. B.J.Hathaway and D.E.Billing, Coord.Chem.Rev., 5, 143 (1970)

10. B.J. Hathaway, Structure and Bonding, 57, 85, 109 (1984)

11. H.B.P. Lever "Inorganic Electronic Spectroscopy ", 2 nd Ed. Amsterdam, p.507 (1984) 